\title{
НАРОДНЫЕ ВИДЫ СПОРТА ТУВИНСКИХ КОЧЕВНИКОВ В ФИЗИЧЕСКОМ ВОСПИТАНИИ МЛАДШИХ ШКОЛЬНИКОВ
}

\section{FOLK SRORTS OF TUVINIAN NOMADS IN THE PHYSICAL EDUCATION OF YOUNGER SCHOOLERS}

\author{
I. Mendot \\ E. Mendot \\ E. Mendot
}

Summary: This article examines the national folk games of the nomads of Tuva as elements of a physical education lesson with younger schoolchildren. The authors give a brief description of the games of the nomadic people, determine the historically established types of horse racing, the features of which turn out to be an effective mechanism in the arsenal of a physical culture teacher. In addition, the article proves the need to familiarize junior schoolchildren with the culture, traditions and customs of indigenous peoples by means of the discipline «Physical culture». The authors emphasize that the use of elements of folk games in the practice of teaching physical culture helps the teacher to realize the tasks of educating a harmoniously developed personality, combining spiritual wealth, moral purity and physical perfection. The article emphasizes that through the conduct of national traditional games in the classroom, it is possible to influence the level of development of the interest of primary school students in the study of multinational culture and art; to increase motivation to study the subject «Physical culture»; to form in students such qualities as friendliness, tolerance, independence, dexterity, quickness, ingenuity, respectful and caring attitude towards pets and nature; contribute to the preservation and strengthening of health.

Keywords: physical culture, game, people, history, horse racing, competitions, running, walking, physical qualities.
Мендот Инга Эрес-ооловна

к.п.н., старший преподаватель, Кызылский педагогический колледж; ФГБОУ ВО «Тувинский государственный университет», г. Кызыл, Республика ТываРФ

Мендот Элла Эрес-ооловна к.n.н., дочент, ФГБОУ ВО «Тувинский государственный университет», г. Кызыл, Республика Тыва РФ menella2013@yandex.ru

Мендот Эмма Эрес-ооловна стариий преподаватель, ФГБОУ ВО «Тувинский государственный университет», г. Кызыл, Республика

ТываРФ

Аннотация: В настоящей статье рассматриваются национальные народные игры кочевников Тувы в качестве элементов урока физической культуры с младшими школьниками. Авторами даётся краткое описание игр кочевого народа, определяются исторически сложившиеся виды конного бега, особенности которых оказываются эффективным механизмом в арсенале преподавателя физической культуры. Кроме того, в статье доказывается необходимость приобщения младших школьников к культуре, традициям и обычаям коренных народов средствами учебной дисциплины «Физическая культура». Авторами подчёркивается, что использование элементов народных игр в практике преподавания физической культуры помогает учителю реализовать задачи по воспитанию гармонически развитой личности, сочетающую в себе духовное богатство, моральную чистоту и физическое совершенство. В статье подчёркивается, что через проведение национальных традиционных игр на уроках возможно повлиять на уровень развития заинтересованности учащихся начальных классов в изучении многонациональной культуры, искусства; повысить мотивацию к изучению предмета «Физическая культура»; сформировать у обучающихся такие качества, как дружелюбие, толерантность, самостоятельность, ловкость, быстроту, смекалку , уважительное и бережное отношение к домашним животным и природе; поспособствовать сохранению и укреплению здоровья.

Ключевые слова: физическая культура, игра, народ, история, скачки, состязания, бег, ходьба, физические качества.

Считаем целесообразным привести краткую историческую справку об особенностях конного спорта в Республике Тува, элементы которого могут оказаться эффективным средством развития младших школьников в процессе преподавания физической культуры в школе.

Кочевой образ жизни тувинского народа является основой его хозяйственной деятельности. Глубинные знания изменчивых климатических условий, растительного мира и рельефа местности сформировали представления об основах содержания скота. Этот фактор обуславливает сезонные перекочевки на определенные территории. В связи с этим сформировалось особое на- 
циональное самосознание, что нашло своё отражение в жизненном укладе тувинских народов. Именно эти особенности и предполагается использовать на уроках физической культуры с младшими школьниками.

На основе концепции «Модернизация российского образования на период до 2020 года» и закона «Об образовании в Российской Федерации» (2018), Министерством общего и профессионального образования Республики Тува разработана «Концепция воспитания человека в общеобразовательных учреждениях в Республике Тува», которая направлена на формирование национального самосознания и традиционной физической культуры, овладение системой общечеловеческих ценностей. В концепции особенно подчеркивается роль этнокультурных компонентов в физическом воспитании молодого поколения. Традиционная физическая культура должна формироваться на основе национальных видов спорта, поскольку они, несомненно, обладают огромным развивающим потенциалом.

В жизни местных кочевников Тувы, как и в других районах расселения скотоводов, конь играл большую роль, прежде всего, как средство передвижения: многочисленные перекочевки, выпас скота, перевозка грузов и многое другое совершалось с его помощью [1]. Уже ранние кочевники ценили лошадь. Лошадь - незаменимое животное для кочевого образа жизни тувинского человека.

Авторитетные исследователи-историки С.И. Вайнштейн, Ф.Я. Кон отмечали в своих научных трудах, что тувинский конь очень терпелив к морозу и хорошо переносит летнюю жару, которая в Туве бывает подчас невыносимой. Тувинцы с испокон веков выращивали местную породу лошадей (аъттар). Они были низкорослыми, с мохнатой гривой и шерстью, чрезвычайно выносливы и неприхотливы [2].

Национальные виды спорта тувинских кочевников (а именно конные скачки) являются одним из важнейших элементов народной культуры. В них наездники демонстрировали свою силу, ловкость, двигательные навыки. И в настоящее время в период проведения традиционных праздников «Наадым» конные скачки и борьба «хуреш» находят своё широчайшее применение.

В социалистической Туве конные скачки стали приобретать новое значение и размах. Объясняется это плановым выращиванием лошадей, появлением коллективных, государственных лошадей, введением ветеринарной службы, улучшением породы и увеличением голов. Данные факторы неизбежно повлияли на тенденцию исчезновения тувинских лошадей, которые остались только в отдаленных заграничных районах
(Барун-Хемчикских, Бай-Тайгинских, Овюрских, МонгунТайгинских кожуунах) Республики Тыва. В конце 90-х начале 2000 годов пришлось заново разводить лошадей тувинской породы. С тех пор начался повышенный интерес к истории национальных видов спорта, особенно к конным скачкам, наблюдается процесс его возрождения, воссоздания традиций и национальной культуры.

Согласно историческому подходу « <...> национальные виды спорта степных кочевников - это сочетание специфических самобытных игр и физических упражнений, характерных для отдельных народностей, сохранения культуры и традиций, или упражнения обусловлены характером трудовой деятельности, или множеством неповторимых, своеобразных упражнений придуманных народом для развлечения, одновременно развивали свои психофизические качества, которые необходимы для жизни» [6, С.67].

По мнению В.В. Ягодина, культура каждого народа содержит большое количество народных видов спорта и игр, и среди них очень много уникальных и самобытных. И даже в современное время лошадь - незаменимое средство для чабанов-кочевников, так как они по сезону года меняют стоянки, что необходимо для кардинально отличающегося зимнего, весеннего, летнего, осеннего ухода за животными.

Таким образом, В.В. Ягодин рассмотрел народную физическую культуру и упражнения с исторической точки зрения, отметив, что проведение скачек древнетюркским способом является характерной чертой лишь некоторых народов Сибири: тувинцев, бурят, монголов и алтайцев. Однако на различных территориях и у различных этносов наличествуют свои характерные черты в правилах проведения скачек и игр, которые проявляются в условиях местности, в протяженности дистанции, в составе участников и т.д. Например, по своему стилю и особенностям тувинские скачки отличаются от казахской «кок-пар» («игра с тушей козла»), «кыз-бор» («волк-дева»), кыргызской игры «кыз-куу» («догони девушку»), где жених должен догнать свою невесту, «байга» («гладкая скачка»), «жорга жорыс» (скачка на иноходцах (женщины - 1-3 км, мужчины - 2-6 км), конные пробеги (суточные - 25-100 км и многодневные - 200-500 км) и другие [6, С.107].

Конные состязания в Туве, например рысаков, происходят следующим образом. Кони выступают без нарядов и сёдел. Допустимы только одни удила без металлических украшений. Перед стартом выстраивают всех лошадей и проводят перед публикой с целью представления каждого скакуна зрителям-болельщикам. Протяженность маршрута составляет примерно 30-40 км. Когда все лошади построены, дают команду «Старт!» наезд- 
ники с криком и свистом, крутя над головой плетками, вырываются на «беговую дорожку». Состязания молодых скакунов проводятся на более коротких дистанциях (5-10 км); на следующий год увеличивают дистанции этим лошадям до 10-15 км [5, С.492]. Одновременно в соревнованиях могут участвовать два вида иноходцев «челер» (при беге четыре ноги чередуются) и «чыраа» (правая передняя и правая задняя ноги одновременно поднимаются и опускаются, затем левая передняя и левая задняя нога, при этом скорость всегда одинакова) [5, С.36]. Это национальные конные скачки - один из самых древних видов спорта великих степных кочевников. Их проводили на различных народных праздниках, например при праздновании традиционного праздика кочевников-животноводов «Наадым» в честь получения хорошего урожая. Данный праздник «Наадым» сопровождался гулянием, играми и состязаниями - борьбой «Хуреш», стрельбой из лука, конными скачками [3].

Таким образом, цель настоящего исследования - описать эффективные приёмы работы с младшими школьниками на уроках физической культуры через приобщение учащихся начальных классов к народным традициям, обычаям, играм степных кочевников.

В круг задач входят:

- описание методики проведения национальных игр кочевников (на примере игры «Скачки») в условиях урока физкультуры в младшей школе;

- демонстрация развивающего и обучающего потенциала национальных игр в процессе преподавания учебной дисциплины «Физическая культура».

Игры - один из компонентов культуры, результат народного творчества. В них отражены традиции народа, вековой уклад его жизни и быта. Лучшая иллюстрация этого - национальные игры и состязания. В связи с этим актуализируются слова одной из монгольских пословиц, которая гласит: «Хочешь узнать, что за народ живет в стране, взгляни на игры его детей».

Как отмечают В.Ф. Мишенькина, И.А. Рогов, А.А. Гераськин, О.С. Шалаев, игра - это важное средство в системе образования и воспитания подрастающего поколения, она включает ребенка в жизнь, в общение с окружающими, с природой, способствует получению знаний, трудовых навыков, улучшению двигательной деятельности. Наличие соревновательного элемента в естественных видах движений позволяет использовать народные игры для подготовки к занятиям по различным видам спорта. Правильный подбор игры в соответствии с возрастными и физическими особенностям детей приобретает особое значение в воспитании у школьников чувства коллективизма, активности, ини- циативы, сознательной дисциплинированности, настойчивости в достижении поставленной цели, смелости [8]. Названные исследователи подчеркивают, в частности, характерную особенность подвижной игры, заключающуюся в её комплексном воздействии на организм и на все стороны личности детей. В настоящее время определены обязательные требования к школьному образованию, ориентированные, в том числе, на приобщение детей к социокультурным нормам, традициям семьи, общества и государства, на становление гражданина, любящего свой народ, родину, с уважением относящегося к культуре, традициям и обычаям своего народа и других народностей. Неоценимую роль в поликультурном образовании занимает «игра». Обращение к опыту народных игр имеет большое значение, поскольку, это помогает подготовить обучающихся к пониманию культуры, к признанию окружающего разнообразия. Следует отметить, что у степных кочевников преобладают подвижные, командные состязания. Любая игра, попадая в иную среду (в зависимости от условия бытования) получает дальнейшее развитие и модифицируется в новый вариант, но с сохранением основного сюжета.

Как отмечает В.В. Семянникова, важным является то, что в играх воспитываются психофизические качества: ловкость, быстрота, выносливость, сила, координация движений, равновесие, умение ориентироваться в пространстве [7]. Народные игры являются одним из традиционных средств этнопедагогики. Народные игры степных кочевников - средство обучения и воспитания, сохраняющее свою исходную и наиболее ценную функцию, обеспечивающую самообразование ребенка через рефлексию. Она есть отражение образа жизни, национальных традиций, обычаев. Это часть народной педагогики, которая, опираясь на активность ребенка, всеми доступными средствами обеспечивает всестороннее развитие и приобщение его к культуре своего народа.

В качестве иллюстрации высказанного выше тезиса представляется возможным привести детскую игру «Аъттар чарыжы» (конные скачки) степных кочевников. Обучающиеся играют в условиях спортивного зала. Количество участников не ограничивается. Если место не позволяет сразу многим принять участие в скачке или не хватает инвентаря, то игру следует проводить группами (по 6-10 человек), т.е. проводить скачки заездами.

Преподаватель должен обратить пристальное внимание на инструктирование перед началом игры: заранее определяется старт и финиш заезда. Расстояние произвольное. По команде учителя все участники игры (заезда) верхом на своих «лошадях» подходят к линии старта, левой рукой держась за «коня», правая рука свободная (рис. 1). 


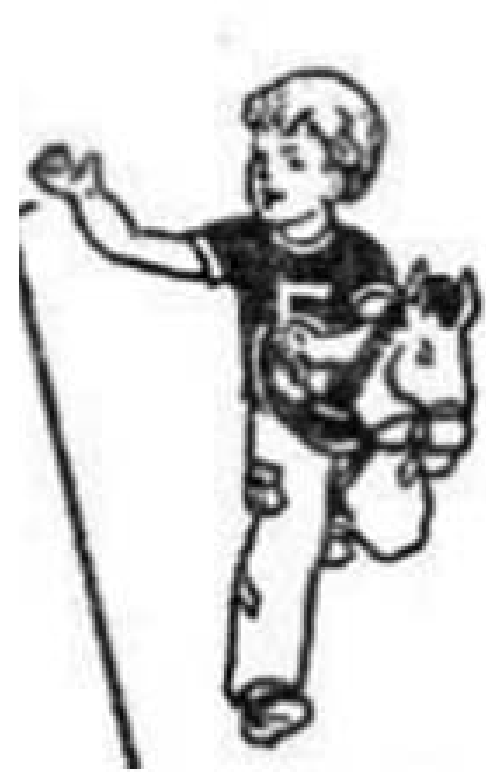

Рис. 1. Иллюстрация положения рук учащегося во время игры «Аъттар чарыжы» (конные скачки)

Во время «скачек» правой рукой следует похлестывать кнутом скакуна, имитируя действия настоящего всадника. Соревноваться можно с учётом следующих видов бега лошади:

1. Шошкудары - бег трусцой, в медленном темпе.

2. Маннадыры или ылгын - бег обычный, но в быстром темпе.

3. Даалыктадыры - (галоп) - прыжки вперед двумя ногами. Правая (левая) нога впереди, левая нога немного назад или ноги вместе (впереди стоящую ногу не менять).

4. Челдирери - (идти рысью) - бег приставными шагами (нельзя менять положения ног), т.е. впереди стоящую ногу не менять.

5. Чырааладыры - (семенящий бег) - бег должен происходить шагами длиной не более чем стопа или маленькими шагами. Во время движения все тело расслаблено, руки двигаются свободно или опущены вниз. Приземление приходится на носок.

6. Саяктадыры - (иноходь) то же, что и 4 упражнение, но, постоянно меняя впереди стоящую ногу, т.е. вперед выносится другая нога после приставного шага; прыгать нельзя.

7. Аралчалаар - смешанный аллюр «рысь и иноходь».

Победителем становится тот, кто первым пересечет линию финиша.

Инвентарь: «Лошадки» - это прутики изготавливаются из мелкого тальника (ивняка). Длина (от 120 до 130 см) должна соответствовать возрасту и росту детей. Вместо прутиков в качестве «лошади» можно использовать гим- настические палочки.

Правила игры:

1. Не разрешается переступать линию старта.

2. Запрещается менять объявленный способ бега (скачек). В противном случае результат не засчитывается.

3. Нельзя касаться друг друга ни «конем», ни какими-либо частями тела.

Игра «Скачки» эмоциональная, веселая, улучшает функциональные возможности организма учащихся начальных классов. Эти семь способов бега лошади может служить подводящим упражнением для совершенствования специальных беговых легкоатлетических упражнений при подготовке обучающихся к спортивной игре «баскетбол». Следует отметить, что данные упражнения применимы также в средних и старших классах. Их представляется возможным использовать на разминке. Основная задача - развитие ловкости, быстроты и прыгучести, формирование правильного способа бега во время передачи и получения мяча. Кроме того, улучшается общая координация движений, развивается способность целенаправленно владеть своим телом в соответствии с задачей и правилами игры.

Народная игра «Скачки кочевников» служит для разогрева и укрепления мышц голеностопного сустава, стопы, а также развития мышц задней поверхности бедра и икроножных мышц, а также групп мышц, ведущих бедро.

Таким образом, народные игры и беговые упражнения с элементами способов бега лошадей могут служить средством разминки и тренировки, способствующим повышению работоспособности и физических показателей в легкой атлетике. Они развивают не только технику бега, но и силовые качества учащихся и положительно влияют на координацию движений, осанку, положение тела, рук и головы, благотворно влияют на дыхательную систему, опорно-двигательный аппарат. Во время урока, если учащиеся допускают ошибки при выполнении упражнений по технике элементов способов конного бега, четко предложите детям быстро их устранить.

Соревновательный и игровой метод повышает интерес учащихся, способствуя лучшему выполнению физических упражнений, повышению результатов по физической подготовке. Практикой физического воспитания подтверждается, что у учащихся начальных классов различные физические упражнения и игры, вызывают интерес к выполнению, поэтому необходимо как можно больше разнообразить средства и методы. В связи с этим на наш взгляд, весьма эффективным средством комплексного совершенствования двигательных 
качеств являются народные игры и состязания, которые могут, применены на уроках физической культуры. Одним из основных путей всестороннего развития двигательных качеств с использованием народных физических упражнений и игр, ведет к обучению различным двигательным умениям и навыкам, и целенаправленно влияет на воспитание всех качеств учащихся начальных классов. Тувинские народные подвижные игры и спортивные состязания степных кочевников не должны быть оставлены без внимания в настоящее время.

\section{ЛИТЕРАТУРА}

1. Курбатский Г.Н. Тувинские праздники / Г.Н. Курбатский. - Кызыл: Тувинское книжное издательство, 1973. - 90 с.

2. Курбатский Г.Н. Тувинцы в своем фольклоре / Г.Н. Курбатский. - Кызыл: Тувинское книжное издательство, 2001. - 463 с.

3. Майны Ш. Б. Народные игры в традиционной праздничной культуре тувинцев: историко-культурологический анализ / Ш.Б. Майны. - Кызыл: Изд-во ТувГУ, 2018. - 114с.

4. Мендот Э.В. Конные скачки кочевых народов / Э.В. Мендот, В.Б. Монгуш // Научный электронный журнал «Меридиан». - Вып. 2 (36). - 2020. - С. 492494.

5. Мендот Элла Э., Мендот Эмма Э., Мендот И.Э. Конные скачки в Туве / Эл.Э. Мендот, И.Э. Мендот, Эм.Э. Мендот // Colloquium-journal. - №12-4 (36). - 2019. - C. 36-38.

6. Мендот Эмма Э., Мендот ИЭ., Мендот Элла Э. История и развитие конных скачек в Туве // Материалы международной научно-практической конференции (31 октября 2017 г.) - Самара: Издательство «Поволжская научная корпорация», 2017. - С. 48-50.

7. Семянникова В.В. Организационно-методические основы подвижных игр: учебное пособие [Электронный ресурс] / В.В. Семянникова. - Елец: Елецкий государственный университет им. И.А. Бунина, 2011. - 96 с. - Режим доступа: по подписке. - URL: http://biblioclub.ru/index.php?page=book\&id=272302 (дата обращения: 30.09.2020).

8. Подвижные игры во внеклассной работе общеобразовательной школы: учебное пособие [Электронный ресурс] / В.Ф. Мишенькина, И.А. Рогов, А.А. Гераськин, 0.С. Шалаев; Государственный комитет Российской Федерации по физической культуре и спорту; Сибирский государственный университет физической культуры и спорта. - Омск: Сибирский государственный университет физической культуры и спорта, 2003. - 108 с.: схем., ил. - Режим доступа: по подписке. - URL: http://biblioclub.ru/index.php?page=book\&id=274874 (дата обращения: 30.09.2020).

9. Ягодин В.В. Народные традиции в физической культуре / В.В. Ягодин. - Екатеринбург: Изд-во Уральского государственного педагогического института, 1992. -155 C.

() Мендот Инга Эрес-ооловна, Мендот Элла Эрес-ооловна (menella2013@yandex.ru), Мендот Эмма Эрес-ооловна.

Журнал «Современная наука: актуальные проблемы теории и практики»

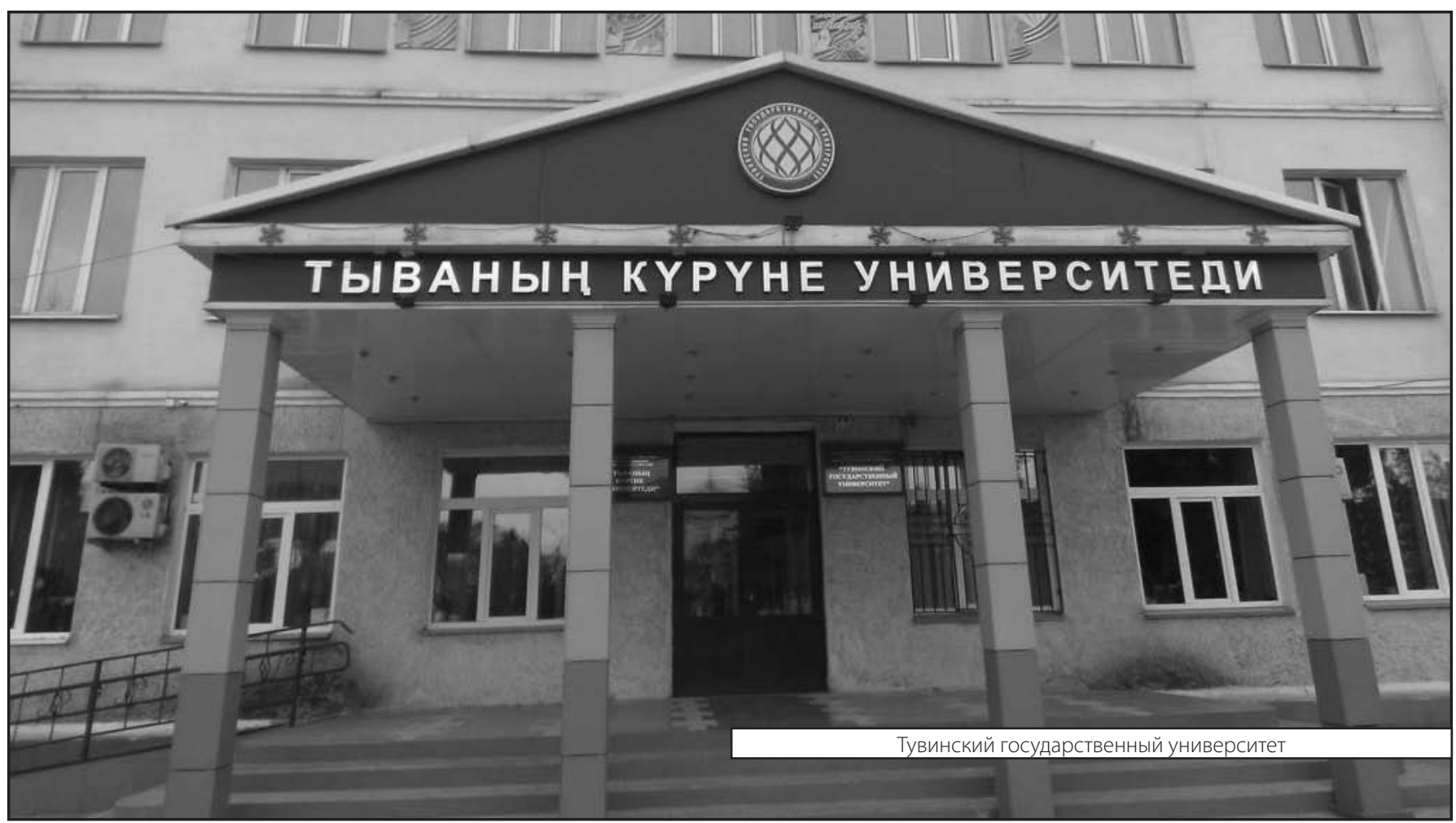

